\title{
The challenge of inclusive cities
}

\author{
Anastasia Repeva ${ }^{1 *}$, Natan Adjidé ${ }^{2}$ \\ ${ }^{1}$ Moscow State University of Civil Engineering (National Research University), Yaroslavskoye \\ Shosse, 26, Moscow, 129337, Russia \\ ${ }_{2}^{2}$ École Spéciale des Travaux Publics et du Bâtiment, (ESTP Paris), 2 rue Gustave Eiffel, Paris, 10430 \\ Rosières près Troyes, France
}

\begin{abstract}
The purpose of this article is to establish a link between lack of accessibility and social unhappiness. This current scenario will be considered in the work to solve this problem, to present technology as a solution. Despite the fact that we can prove the effectiveness of technologies for inclusion and, therefore, the quality of life, we will consider the complexity of this system. The article concludes on issues of confidentiality, the need for technology, the participation of science in constructive changes in society; change based on a social disability model; by ensuring all these criteria, technology would help shape a city where everyone could live and thrive, regardless of their physical or mental condition.
\end{abstract}

\section{Introduction}

By definition a city is an area relatively important whose inhabitants have diverse professional activities and whose population is at least of 2000 inhabitants. These highlights to main ideas. The idea cities are made by the people that live there and the idea the city must provide a career. That means designing a city is not only a matter of architecture and design, but it also questioned our ability to provide employability and social inclusion for each individual.

Despite the desire of a society with a sustainable conscience, countries are missing the accessibility component, which is an integral part of sustainable development. For a country to be sustainable it must be accessible to all. Sadly, it is true that accessibility is perceived not as a common goal but as a measure dedicated for a small part of the population. To create fully inclusive sustainable cities, we should proceed a hard task: a change of mind. That means we need to change the general perception and the clichés that embrace these people. For that, reference should be made on the disability studies. Disability studies is "an academic discipline that examines the meaning, nature, and consequences of disability". Studies analyzed the handicap from a multidisciplinary point of view: social factors, cultural factors and political factors.

${ }^{*}$ Corresponding author: repevaam@mgsu.ru 


\section{Methodology and approach}

As we mentioned it earlier, our study is based on the "Disabilties Study" that will help us answer questions such as: what are the barriers to inclusion? What solutions are the most feasible? What is the reality of the issue? After going through numerous writings and observations, we have selected the crucial elements illustrating the social character of this problem. Because indeed, it is important to emphasize, therefore, that this study, which at first glance seems to be a scientific problem, is actually a social problem. And it is around the social model of disability that we can present the role of science and technology in inclusion. In this scientific study, it is essential to engage in a more "philosophical" reading of each element. So we then brought together technological innovations and established the link between these technologies and a social aspect of the problem of inclusion. We were then able to assess the correlation between technology and sociology in this study.

\section{A social challenge rather than a scientific one}

How can we make our cities more inclusive? Here is the question that many engineers, urban planners and architects are trying to answer. In reality, many measures, which we will discuss below, have already been put in place. And yet, the general feeling is not in favor of the improvement of inclusion. We often think that the question of disability only concerns our infrastructures. But, it's more than that. It's also concerns the function itself of our buildings. Have you asked yourself what is the connection between the right to love and the difficulties of accessibility in cities? For example, in cinemas two places for disabled people, side by side, do not exist everywhere. So, we could consider that people with disabilities, under normal conditions, have trouble to do "romantic activities" such as going to the cinema as "regular people". If accessibility is reduced, then they are deprived of full social activity. Elderly people, for example, who have more and more trouble moving, come out, less and less.

We also cannot deny that the inclusion is not progressing much because of a lack of action. This lack of action until now was justified by the existence of two models of disability. The first model is about rehabilitation. This model is based on a scientific approach of people with disabilities. They are victims of physical deficiencies and must, through science, enter into what appears to be normalcy. The objects designed to help them only allow them to move in a normal or even normalized society. The second model is the one defended by the Disability Studies. This model, unlike the rehabilitation model, does not question the person but the society itself. Since the Bloch-Laine's report in 1968, the attention began to be focused on a development of our society. In this model, the barriers put in place by society are tackled.

Thereby if we are talking about society, we have to talk about rights and human rights. There are different types of disabilities: physical, sensory, intellectual (mental), psychic (schizophrenic ...). Whatever the form of the handicap is, it must be approached as a question of Human Rights. The Convention is the first international legal instrument and was created by people who were themselves concerned by the subject. It entered into force on May 3, 2008. The convention in the hierarchy of laws has at least the same level as a constitution. However, the work necessary for its dissemination has not been done and this document is not sufficiently known.

The existence of laws then proves the need to format society. And it is also towards this perspective that the European Union is turned. On December 12, 2017 the Council of Europe defended "the design of products, equipment, programs and services that can be used by all, as far as possible, without requiring adaptation or special design". Yet very few projects go in this direction. On the contrary, the political measures that might have been 
put in place, only seem to criticize an astronomical cost generated by accessibility measures for people with disabilities. In reality, the cost of accessibility represents less than $1 \%$ of the total cost of construction works. Moreover, it is estimated that tourism loses between 15 and $20 \%$ of its market due to inadequate infrastructure for people in situation of handicap.

Fortunately, the idea that the question of disability in our infrastructure is a social issue, is beginning to permeate people's minds. Let's see the example of the architect Rudy Riciotti. This architect builds the MUCEUM of Marseille (Museum of European and Mediterranean civilizations in Marseille, France). He also builds the Philharmonic of Potsdam, Germany. For him the social model of disability disrupts the vision of social housing. According to him the accommodation belongs rather to the republic than to the people itself. But Individual requests, for the renovation of historic monuments, for example, must be considered and a solution of understanding can be found to satisfy the users but also his personal vision. In his project of Muceum, areas that previously were not accessible, became accessible thanks to ramps of access. Meeting the needs of people with disabilities should be a moral duty for construction professionals. Like any social movement, it takes a certain amount of time to be integrated by society. A few years ago, who could have considered automatic doors as a normality for shopping centers, hospitals, railway stations ... This measure, which was initially intended to facilitate access to people with disabilities has, over time, become a basic standard for this type of building. Maybe in the future the automatic doors will be the norm also for individual personal buildings.

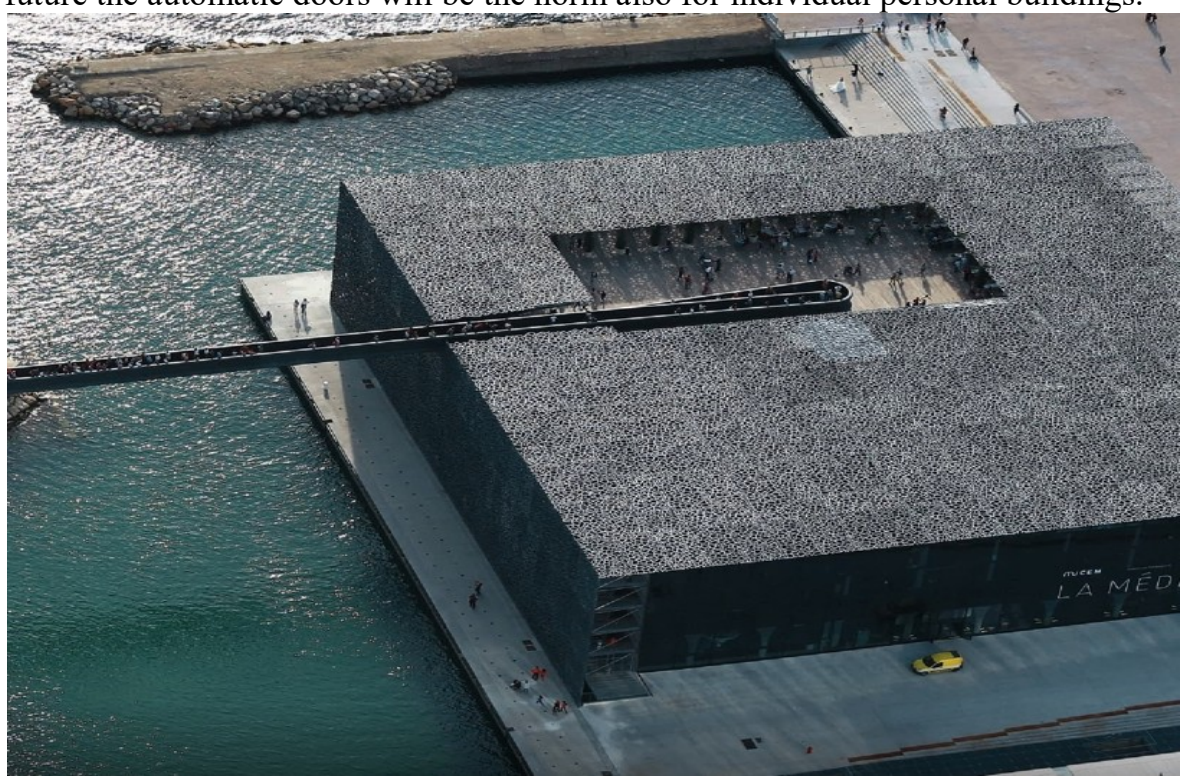

Fig. 1. Ramps and bridges connecting two sites of the MUCEUM 


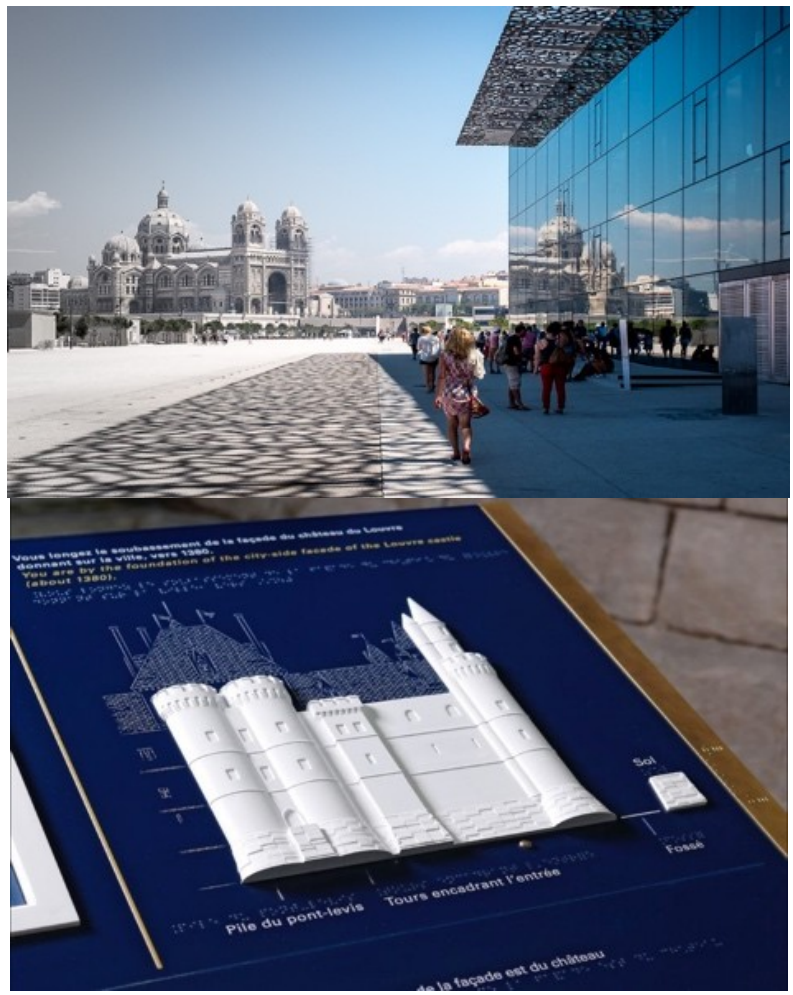

Fig. 2. Sensory experiments and brail writing within the museum

\section{Technology: instrument of inclusion}

For several years, we have been hearing about the notion of smart cities. These cities seek to respond to the growing population of our cities and the increase in the number of people with disabilities of any kind. What is a smart city? A smart city is a city that uses so extensively devices connected in order to provide services as the most sustainable and efficient as possible. In homes we have all heard or seen gadgets that can be used to automate some of the tedious tasks. On a scale much larger, smart cities use services primarily digital, based on a multitude of devices connected, to improve today crowded cities and therefore chaotic. A classic example is the parking meter. If we give users an application that indicates where the available spaces are, that would allow them to save time, money and reduces frustration, stress, congestion and pollution. Now imagine that you are living with disabilities and you are looking for parking for people with reduced mobility. A smarter city equipped with sensors could know which spaces reserved for people with reduced mobility are empty and where.

According to the UN, by 2050 more than 6.4 billion people will be urban, which represents nearly two-thirds of the world population. In addition, the world's population is aging, and, with age, health problems, impairments and disabilities are increasing. Imagine a city where a person in a wheelchair, or a woman pushing a stroller, can plot a route to the local park using sidewalks and avoiding the barriers. This person would connect wirelessly to the park itself and receive notifications of events to come and may even participate in an interactive lesson on trees and flowers.

The global market of smart cities is expected to reach 1565 billion by 2020 , and the opportunity of such a growing economy involves intrinsically the opportunity to engage, 
inform and improve the lives of citizens. Technologies should provide people with disabilities a better access and greater participation in the life of the city. New interconnectivity solutions will improve solutions for mobility users. However, smart cities should be defined not as a means of improving infrastructure but as an opportunity to improve the lives of all citizens. In addition, creating livable and sustainable cities for people with disabilities would benefit everyone. Indeed, measures to make it more inclusive often have effects on the quality and use of all users. Let's recall the idea of a Universal Design: "Disability is a natural part of the human experience that does not diminish one's right to fully participate in all aspects of community life." This is why to be viable; it must involve everybody. In addition, politicians must strive to reduce the digital fracture which often prevents the older or disabled to have a full access to technology.

The technologies that we want to integrate into smart cities offer the possibility of making cities more welcoming but will be unnecessarily limited if they do not integrate with assistive technologies for example with screen readers, devices auditory, braille displays, and technologies used by people to mobility reduced. These technologies must help people overcome everyday obstacles and fight against systematic inequalities that can sometimes affect the quality of life. For example, from the economical point of view, we consider that nearly half of the American population aged over 65 is classified " economically vulnerable ". Added to this, almost $80 \%$ of the elderly are concerned with chronic disease such as disease Alzheimer. And we consider that almost $15 \%$ of the spending of the American elderly are related to health.

The researchers calculated to an average cost of $\$ 30500$; the cost (direct and indirect) for a family with a disabled child. This can lead to poverty which itself leads to isolation. The inaccessibility to community events, limited transportation options and limited social interactions are the main obstacles to a good quality of life and affect negative the feeling of well-being. Technology companies and people with disabilities met on November 16, 2016 in Vienna to discuss the relationship between new technologies and people with disabilities. There are two types of technologies: assistive technologies and technologies of accessibility to the public. If both differ in their application, they can restore the inequalities experienced by people with disabilities in their lives. For this, it must have an appropriate design. To better understand what people with disabilities, need, companies include people with disabilities in teams. Here are different testimonials:

Yannis Vardakastanis, President of the European Disability Forum stated: "Technologies should promote the inclusion and participation of persons with disabilities in all phases of life and should not produce more exclusion and discrimination. This magnificent opportunity of inclusiveness should not be lost."

Adina Braha-Honciuc, Government Affairs Manager at Microsoft stated: "Advanced technologies like artificial intelligence (AI) can empower people living with disabilities to participate fully in every aspect of society. By ensuring that technology fulfills its needs societal needs, we can empower everyone - not just people with disabilities - to achieve more."

By 2030 , more than $60 \%$ of the world's population will live in cities. When cities become smarter, they cannot afford to leave anyone behind. In the future, cities should meet the needs of vulnerable members of social groups such as families, people with disabilities, indigenous peoples, the elderly and young people. Cities must reinvent themselves in the way they communicate, plan and respond to the complex needs of their citizens. The technological and social innovation allows cities to explore solutions and create the communities more intelligent and interconnected that can improve service delivery, improve the lives of citizens and reduce the poverty urban. Innovation can be a catalyst for change and ensure that our cities and communities are resilient and inclusive for all ages. Most cities are totally hostile to people with disabilities - but with nearly a billion urban 
inhabitants estimated by 2050 , a few cities are undergoing remarkable change.

\section{Case studies}

The first element of which we only speak very little and that affects people with disabilities is fear. The fear of not being able to move in one's own city. The fear of falling on too crowded environments for a blind person to go to the shops, go for a walk in the park, go to work or simply socialize. For example, in the city of Southern Cross, the station has become, at least for the visually impaired or blind, much more accessible. Indeed, a new beacon navigation system sends audio signals to users via their smartphones, providing them with instructions, signaling the breakdown of the escalator. What would have previously been a forbidden zone is no longer. Thus, anyone who is visually impaired, or blind is no longer dependent on any other person who should warn or accompany them. Our current cities are for people experiencing physical (mobility reduced) real obstacles. These obstacles can range from blocked access ramps for wheelchairs to buildings without a lift, through inaccessible toilets, to shops without access without steps. From the same, people experiencing mental disability or autism cannot live in a modern urban environment as the everyday hustle is a "field of sensory mines. "

Most people navigate our cities thanks to different mapping systems like google MAPS for example, yet none of these applications signal the presence of ramps, nothing prevents from high roped street or other elements essential to the movement of people with physical disabilities. In Seattle, for example, while Google Maps sends pedestrians from University Street Station to City Hall via Seneca Street, with its steep 10\% slope, Access Map (created by the Center for Accessible Technology of the University of Washington) sends them via Pike Street - a slope of less than $2 \%$.

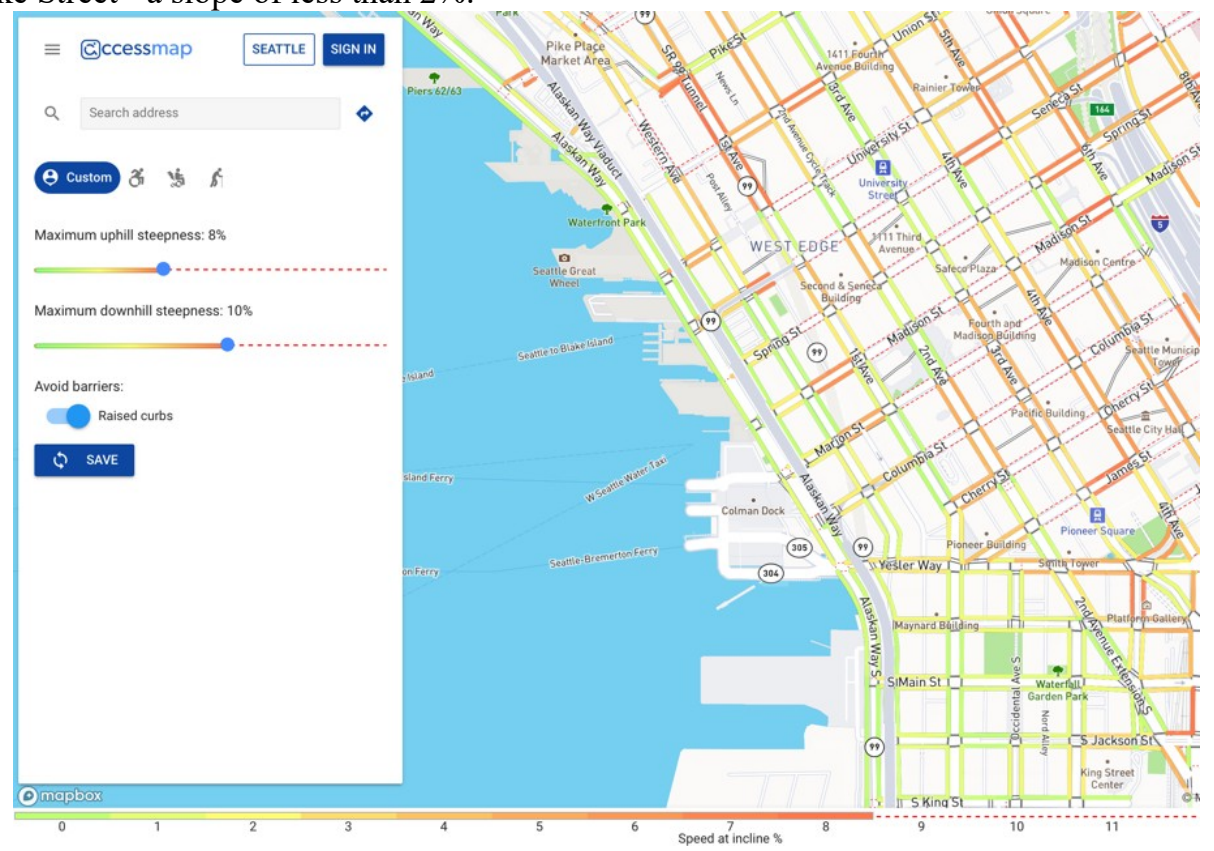

Fig. 3. Presentation of AcessMap

The city of Singapore is experiencing an aging population. Take the CapitaGreen building, for example, in the Central Business District. It is a 40- storey office building completed in 2014 at a cost of 1.3 billion Singaporean dollars. The structure designed by 
Toyo Ito has spaces without columns and a low concierge desk to help people with disabilities to move more easily in the building. Elevator doors stay open longer, general doors are wider, handrails on both sides of stairs and chairs have handles. An auditory induction loop allows clearer communication for those using hearing aids, while Braille instructions, tactile guidance and easy- to- read pictograms help the visually impaired. Disabled people may be hypersensitive to sound, light, and may be overwhelmed by noisy or crowded spaces. Sweetwater Spectrum, a housing project aims to solve this problem. The noise is minimized thanks to silent heating systems and ventilation design. The trimmings and decor reduce sensory stimulation and clutter, with soft colors, neutral tones and a natural or recessed light. The sports complex, holiday and conference of Musholm in Korswr in Denmark is an example of an inclusive sports complex. At the center of the complex is a large circular gymnasium, with a cable car and a climbing wall for wheelchair users and an integrated pulley system. Outside, a ramp of $100 \mathrm{~m}$ rises from the base of the hall to the sky (The ramp can also be used as a wheelchair racetrack.). The 24 rooms of the hotel are equipped with hoists to ceiling curtains electronics, beds that can be automatically raised or inclined, to sink to height adjustable and accessible toilets. At the edge of the water, a private bathing pier is wide enough for wheelchairs and accessible via a ramp. "The accessibility should be felt but not seen. The lack of accessibility, other assumptions, the ideal body and a lack of confidence in people with disabilities are often the main obstacle to diversity", has declared Henrik Ib Jwrgensen, director of the foundation.

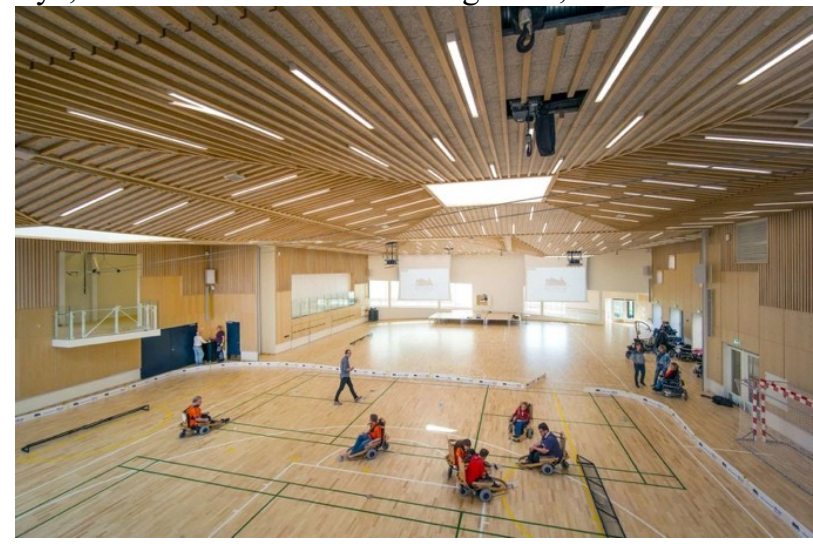

Fig. 4.Accessible sport complex in Korsør

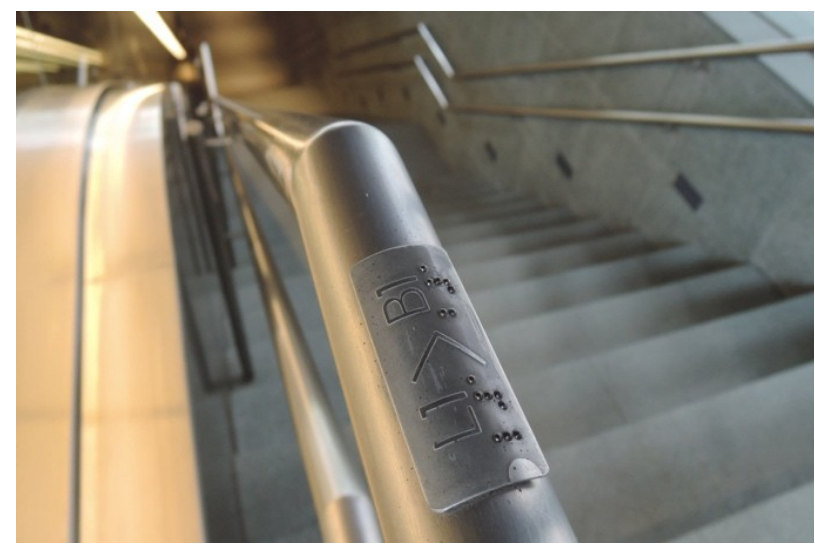

Fig. 5. Brail to indicate the way in the subway

In Chester, Melbourne and other cities more accessible projects are emerging as a result 
of the demands of groups of people with disabilities. Little by little, all our infrastructures should be adapted. What is also important is the implementation of a priority accessibility to communication technologies. It's the first step for accessibility. In fact, a city that understands and embraces the accessibility standards of information and communication technologies ensures that its digital programs and services include people with disabilities and the elderly. The second step is prevention. The third step would be to adopt a policy which is supportive in the action. The latest tool is the " database " solution for digital inclusion in cities. People will find existing products and solutions that can improve the lives of people with disabilities, the elderly, and many citizens living in smart cities. There are finally different examples where it is not the person with a disability who adapts to the city but the latter who is forged in the image of all.

In Latin America for example, a lot of achievement can be cited. Indeed, in Latin America is considered as a good accessibility, an accessibility called invisible to the users' eyes. This accessibility seeks an equivalent design for all, comfortable, aesthetic and safe. It advanced also in the countries of America Latin a problem of "social conscience". If a person in the street meets a person with a disability, she would not have the reflex to offer help. Finally, universal design and accessibility are not limited to the architectural appearance and structural cities.

In Santiago mobile applications have participated in the liberation of people with disabilities. In Chile $13 \%$ of the population is affected by some form of disability. The National Fund for people with disabilities, created in 1994, make possible an analysis of the management of the situation. Based on the analysis The Startup SIGA Chile has developed a website and an application that facilitates navigation for people 's mobility reduced. In Latin America, but also around the world, buses are the most used means of transport. Mexico City, for example, introduces buses and carts with ramps. The buses are equipped with a system to reduce the height of the bus during the climb.

In Bolivia, the HI association help people with disabilities to integrate into society. Bolivia, like other countries in South America, is particularly vulnerable to natural disasters. HI plans take into account people with disabilities.

The company Chennai Corporation in partnership with the "Disability right alliance" has realized in Chennai, an accessible playground. This project presents various elements that distinguish it from other playgrounds. In a first time the park has paths lined with tactile markers for easy navigation of people with a disability visual. The crossing points are designed to ensure a smooth passage for people in wheelchairs. A sand pit and swings at heights of people Wheelchair a Summer placement. These facilities are accompanied by a sensory journey. Finally, for children with some form of autism who may feel overwhelmed by the surrounding noise, there are quieter corners with table games.

In Argentina, in 2002, a legislation passed to promote access to tourist sites. Laws are made to make cities more inclusive but like everywhere the application of these laws is far from perfect. While the Minister of Environment and Public Spaces of Argentina, Eduardo Macchiavelli, announced that Argentina had built in the capital more than 15000 ramps, it is a total plan of 19860 ramps that was initially planned.

\section{Results and discussion}

Technological innovations are, for people with disabilities, a tool of independence. Imagine, shopping centers, stores, schools, offices and medical buildings that are accessible via mobile applications, voice commands and automatic doors. The opportunity for aging communities and people with disabilities to benefit from these new technologies depends on several success factors, we are about to treat.

The influence on the quality of life - Numerous studies have shown that people with 
disabilities tend to isolate themselves. According to some studies, $28 \%$ of young autistic adults would have no social contact, and adults over 60 years living alone are $59 \%$ more likely to experience a decrease in their ability to perform daily activities. The technological improvements of the infrastructure and transport have a positive impact on the way that city dwellers enjoy the city. Smart cities improve the access to social and cultural resources in order to overcome isolation, these communities often face. People with disabilities are faced with significant inequalities in terms of education. The rate of students with disabilities graduates is less than $20 \%$ average. If our schools are not adapted for disabled people, we should a way to make it inclusive. A project from the University of Georgia is developing a "virtual classroom" located in the virtual world Second Life. According to researchers, this virtual classroom "would allow students with disabilities - from the Blindness and low vision to the challenges of learning - to connect with a mentor selected by hand in a space digital." In the virtual classroom, students can meet their mentors as an avatar, set meeting schedules, and roam freely in the virtual world to participate in multiple learning environments. The studies on health continues to assert that the education permanently play a role greatly beneficial in maintaining mental health. For the elderly the mental health is focused around the housing. They want to maintain an affordable and comfortable home life. Nearly $90 \%$ of people over 65 prefer to live on their own but only $43 \%$ of those find it very easy to live as independent. Between urban planning solutions and individual devices, smart city technologies can improve the housing problems by allowing an independent life, minimizing the housing cost housing and helping city officials to better plan an inclusive housing. The efficiency of buildings generated by smart energy technologies can provide savings of the order of $10 \%$ to $25 \%$. The new devices will make life easier by automating difficult tasks and providing guarantees against potential health and safety risks.

Creation of partnerships - Smart city technologies providing solutions to the scale of the system, their deployment requires the participation of all sectors and communities of the city. In Europe, several partnership models are already in place. The European Innovation Partnership on Cities and Smart Communities (EIP-SCC) is an initiative supported by the European Commission that brings together cities, industries, SMEs, banks, research and other smart city stakeholders to develop and implement smart city solutions. In the United States, similar models emerge with even more citizen participation.

An ecosystem - To create a sustainable solution, we have to involve every. All communities have to work as an ecosystem. Let's take the example of Aria, in New York. Aria is a young technology company that uses smart, portable glasses to improve the lives of people with vision loss. Aira connects the visually impaired to a network of " certified agents ", who literally serve as "wearer's eyes". The idea of the installation of screens in real time seems great because these screens can be partially used by people in wheelchairs or people who have limited use of their arms or their legs. People with disabilities expect cities to provide an inclusive transportation system. "Cities could use the technology to make travel more secure and predictable for people with disabilities cognitive". There is for example another case, in the London Underground, (the TUBE). This application called Wayfindr uses Bluetooth to help visually impaired travelers navigate the winding lanes and escalators.

The issue of inclusion and privacy - If the inclusion goes through technology one priority should be put on security. It is necessary to inform and interact with the communities that will benefit from these technologies. And these technologies shall give priority to confidentiality and safety.

The question of adoption - James Thurston said that if we look at the smart cities from the perspective of accessibility, we have the great opportunity to reduce the digital gap which prevents all citizens, including those with disabilities or impairments related to the 
age, to benefit from the digital revolution. However, the use of Internet technology is not limited to a matter of access but involves also a question of adoption. Of the aging population with access to these technologies, only $13 \%$ would be comfortable trying to use a new technology device without assistance. There is a risk that the benefits of such technologies will be limited due to the barriers of adoption. To meet this need, in the US, some computer classes are put in place. There is the "AT \& T's Digital You" training program or Digi Seniors in Chicago, which are training program for aging communities. In New York, OATS (OLA), a non-profit organization, has established the country's largest and most comprehensive municipal technology program, serving a population of more than 20,000. This training helps the aging community to use technology to improve their health, their finances and their civic and social engagement. Six months after the training, 93\% of participants were still using their computer and $89 \%$ said to have maintained their skills and still be able to do what they had learned during the class.

\section{Conclusions}

Although technologies are advancing and evolving, our society and our cities are still based on imagined concepts, years ago. The design of European cities, for example, follows a pattern of the medieval era, despite the expansion of cities. Above all, we must therefore be aware of the problem. Finally, the design of inclusive cities begins with a change of mindset. Furthermore, if we want to increase the inclusion of people with disabilities in our cities, then we need to change the general perception and stereotypes that embrace these people. We have to accept that inclusion only depends on one thing: us. We, our Interpretation of the many current issues and technology management. Our cities of the future will have to respect the evolution of the perception of disability. They must aim for absolute respect for human rights. The new technologies populating our cities will have to ensure flawless security for users. Because if these technologies have a significant impact on the quality of life of all users, a security breach would have a disastrous effect. And let's not forget that technology not only makes people with disabilities independent, but also improves the daily life of all users. By ensuring all these criteria, technology would help shape a city where everyone could live and thrive, regardless of their physical or mental condition.

\section{References}

1. G.L. Albrecht, J.-F. Ravaud, H.-J. Stiker, Sciences sociales et santé. 19 (4) 43-73 (2001)

2. G. Serra-Coch, C. Chastel, S. Campos, H. Coch. Cities. 76, 58-71 (2018). https://doi.org/10.1016/j.cities.2018.01.007

3. D. Bates LLC. [Online]Smart Cities Library(tm). Artifical Intelligence Must Serve Everyone.https://www.smartcitieslibrary.com/artificial-intelligence-must-serveeveryone/

4. G. Melis, M. Tabasso, M. Stroscia, G. Costa. Measuring Transport Equity, 143-157 (Elsevier, 2019) https://doi.org/10.1016/B978-0-12-814818-1.00009-3

5. United Nations. [Online]. Accessible Cities United: Enabling Future Cities to be Smart. https://www.un.org/development/desa/dspd/2017/10/special-event-onaccessible-cities-u united-31-october-2017/.

6. Nations Unies. Convention relative aux droits des personnes handicapées et protocole facultatif. préambule article 1 à 47 . 
7. S. Salman. The guardians articles. [Online]. What would a truly disabled-accessible city look like? https://www.theguardian.com/cities/2018/feb/14/what-disabilityaccessible- city-look-like\#img-12

8. E. Woyke. [Online] Smart cities could be lousy to live in if you have a disability//MIT Technology Review, 2019. https://www.technologyreview.com/s/612712/smart-citiescoule-be-lousy-if-you-have-a-disability/

9. C. Vert, G. Carrasco-Turigas, W. Zijlema et al., Landscape and Urban Planning. 190, (2019), https://doi.org/10.1016/j.landurbplan.2019.103611

10. H. Jeekel. Inclusive Transport. 57-91 (Elsevier, 2019) https://doi.org/10.1016/B978-0$\underline{12-813452-8.00003-7}$

11. F. Santos, A. Almeida, C. Martins et al., Computers, Environment and Urban Systems. 77, 101-173 (2019) https://doi.org/10.1016/j.compenvurbsys.2017.08.007

12. L. Carmichael, E. Prestwood, R. Marsh et al., Science of the Total Environment, 137146 (2020) https://doi.org/10.1016/j.scitotenv.2020.137146

13. N. Vorster, K. Evans, N. Murphy et al., Neuromuscular Disorders, 29(3), 221-230 (2019) ISSN 0960-8966. https://doi.org/10.1016/j.nmd.2019.01.010 